Military Technical College Kobry El-Kobbah, Cairo, Egypt

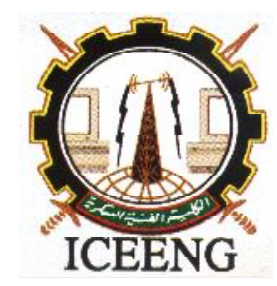

$9^{\text {th }}$ International Conference on Electrical Engineering ICEENG 2014

\title{
Differential Protection Of Bus Bar Based On Artificial Intelligent Approach
}

\author{
By \\ Sameh. M. Elbana*
}

\section{$\underline{\text { Abstract: }}$}

The application of Artificial Intelligent approaches was introduced recently in protection of distribution networks. These approaches started with introducing Fuzzy Inference System, then using Artificial Neural Network .In this research, the application of Adaptive Neuro Fuzzy Inference System for protection of bus bars will be illustrated. The Adaptive Neuro Fuzzy Inference System can be viewed as a fuzzy system, a neural network or fuzzy neural network. The objective of this research is firstly to detect the fault occurrence on bus bar, secondly locating the fault. The fault detector and locator are firstly trained using Adaptive Neuro Fuzzy Inference System technique and then they are tested in diversity of system conditions with respect to the fault types, inception instant, resistance and pre-fault conditions.

\section{Keywords:}

Digital bus bar protection, phasor estimation, current transformer saturation, fault, Adaptive Neuro Fuzzy Inference System (ANFIS) .

* Egyptian Armed Forces 


\section{Introduction:}

Differential protection schemes are applied for high voltage bus bars. Failure - totrip on an internal fault, as well as false tripping of a bus bar during a load service or in case of external fault, both have disastrous effect on the stability of power systems [4]. The challenge of bus differential protection is the issue of false differential current due to CT saturation and ratio mismatch [12]. The bus bar protection can be classified as high impedance and low impedance types [4]. High impedance relays are used to provide low cost bus protection, but have limitations due to complex arrangements and use of multi ratio current transformers. The low impedance measuring principle employs the zone-selective differential current as the operating quantity and the sum of the current magnitudes as the stabilizing signal [5] . The measuring principle must ensure protection with CT saturation on external faults. A low -impedance bus bar protection operates during CT saturation by using a principle, which discriminates between saturated and un saturated wave forms[4] . Recently, many novel differential techniques have been proposed to overcome CT saturation. For external faults, the differential current should be zero, but errors caused by CT saturation can result in a non- zero value [10]. To prevent mal operation, the operating threshold is raised by increasing the bias setting. Raising the bias threshold has detrimental effect on the relay sensitivity as it prevents the detection of in -zone resistive faults. The impact of CT ratio- bias characteristics reduces the sensitivity of the relay [10]. A new digital relaying technique for bus bar protection using phase angle change in sequence current of incoming CT currents and outgoing CT currents [6] and as show in Figure.1. The angle differences of during fault and pre-fault currents signals of incoming and outgoing CT's are the indicators of external or internal faults for bus bar protection[9]. The phasor concepts are used to overcome the current transformer saturation. The major advantage of the proposed technique is that it does not require additional voltage signal for discriminating internal and external faults [9]. Another advantage of method is that it does not use magnitude information of the current only for discriminating the fault and thus over comes the CT saturation issues. The positive sequence component is used as such as a component is available for both unbalanced and balanced faults [9].The mentioned scheme is deterministic computations assuming system modeling based on conventional mathematical tools, and they are not well suited for dealing with ill-defined and uncertain systems, the intelligent computational techniques such as Fuzzy Inference System (FIS), Artificial Neural Network (ANN) and Adaptive Neuro Fuzzy Inference System (ANFIS) as presented in [2\&3] . They can model qualitative aspects of human knowledge and, re-establish the process without plenty of analysis. In addition they restore the processes without employing quantitative analysis. Thus these techniques are fetching great attention in the research environment with the absence of a simple and well - defined mathematical model . 
These models are characterized by non-random uncertainties associated with vagueness and imprecision in real - time system as given in [3].

The article is organized as follow, section I presents introduction about differential protection of bus bars. Section II illustrates the intelligent techniques types and the advantages of using intelligent techniques with the power system protection. Section III presents the proposed method for bus bar differential protection using ANFIS, bus bar modeling using ATP software and ANFIS controller modeling using MATLAB SIMULINK. While section IV illustrates the ANFIS controller training and testing procedure. Section $\mathrm{V}$ presents discussions around the experimental results and the previous work, also the advantages of using ANFIS controller instead of other controller. The conclusions of the research and the advantages of using phasor method are illustrated by section VI. Section VII presents the references.

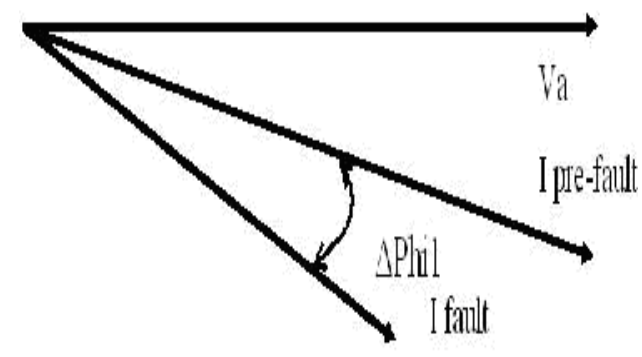

C'T.1

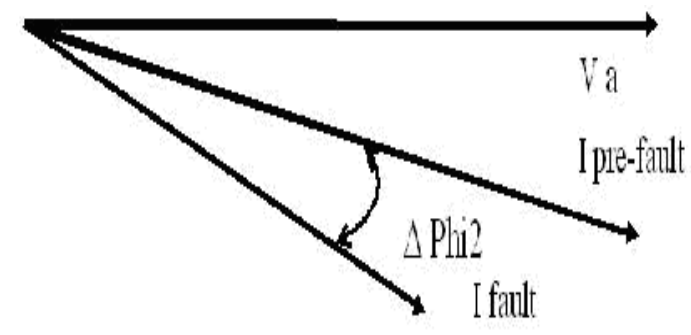

CT-2

Phi I fault - Phi I pre-fault $=$ Phi

Figure (1): Phasor Diagram

\section{The Intelligent Techniques Types:}

The power system protection approaches are based on deterministic computations on a well-defined model of the system to be protected. This results in taking system variation into account as the rules are fixed. They do not have the ability to adapt dynamically to the system operating conditions and to make correct decisions if signals are uncertain. Recently, intelligent soft computational techniques of human knowledge features are required. This intelligent soft computational techniques like the following as illustrated in [3].

a) Fuzzy Inference System (FIS):

Fuzzy system is a non-liner - mapping between inputs and outputs. Fuzzy logic has the 
advantage that the solution to the problems can be cast terms that human operators can understand in form of IF- THEN rules, so that their experience can be used in the design of the controller system . This makes it easier to mechanize tasks that are already successfully performed by humans, on other hand. FIS is, depend on fixed membership functions. It can't be adjusted to compensate the error at the output of FIS controller as presented in [3] as shown in Figure.2.

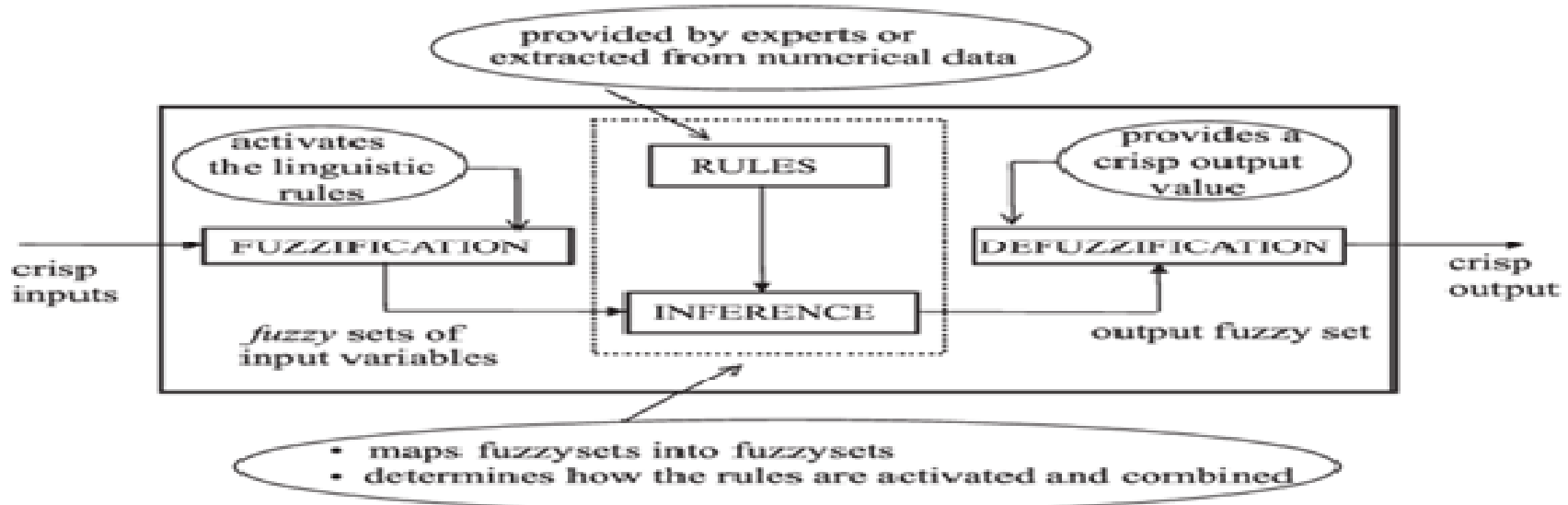

Figure(2): Fuzzy Inference System

b) Artificial Neoural Networks (ANN):

ANN is defined as they are simply a class of mathematical algorithms to solve a number of specific problems. It is has learning facilities which make it able to compensate the error at the output by adjusting the weights. On other hand, it is prohibitive computational effort. The solution of problems can't be cast terms that human operators can understand as given in [3] As Shown in Figure.3.

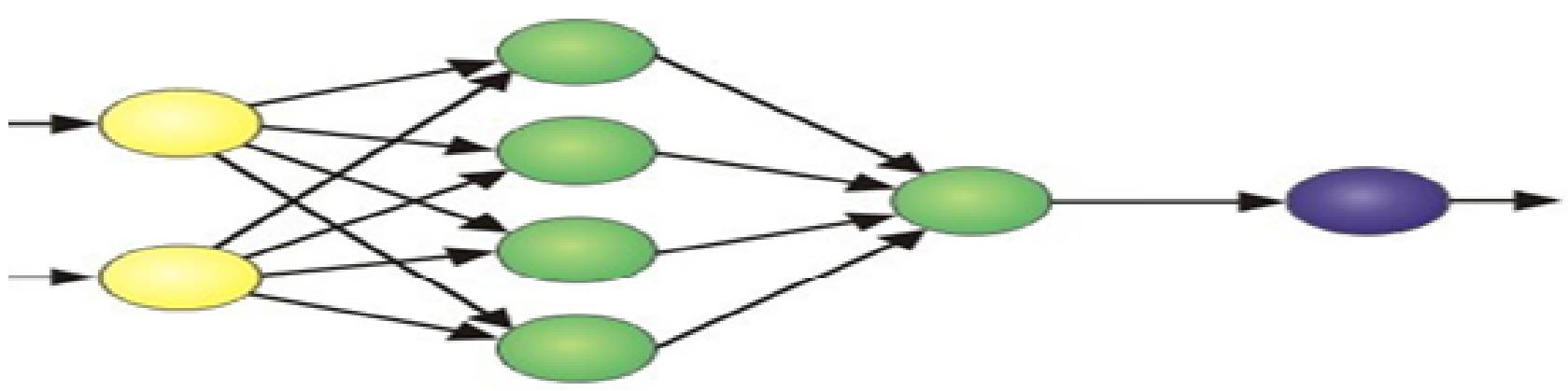

Figure(3): Neural Network Architecture 


\section{c) Adaptive Neoural Fuzzy Inference System (ANFIS):}

It is observed from the study of (FIS ) and (ANN) that the modeling of differential protection system by using any one of them . It will be very complex. The power system operation in transient period cannot be easily described by artificial explicit knowledge, because it is affected by many unknown parameters. These drawback of (FIS) and (ANN) are overcome by the integration between the ( ANN ) technology and the fuzzy logic system, to originate another artificial intelligence technique called .Adaptive Neuro Fuzzy Inference System (ANFIS)As shown in Figure.4. This research is integrating the learning capabilities of (ANN) to the robustness of fuzzy logic systems in the sense that fuzzy logic concepts are embedded also provides a natural frame work for combining both numerical information in the form of input / output pairs and linguistic information in the form of IF -THEN rules in a uniform fashion as presented in [3] As illustrated in equations (1)\&(2). In This research the proposed differential protection relay was applied on $110 \mathrm{kv}$ bus bar using phase angle change in positive sequence current of incoming CT and outgoing CT as shown in Figure.2. The fault detectors and locators are instituted by the (ANFIS) training, and then they are tested in variety of system conditions to ensure the robustness and the comprehensive of the proposed protection scheme as explained in [3].

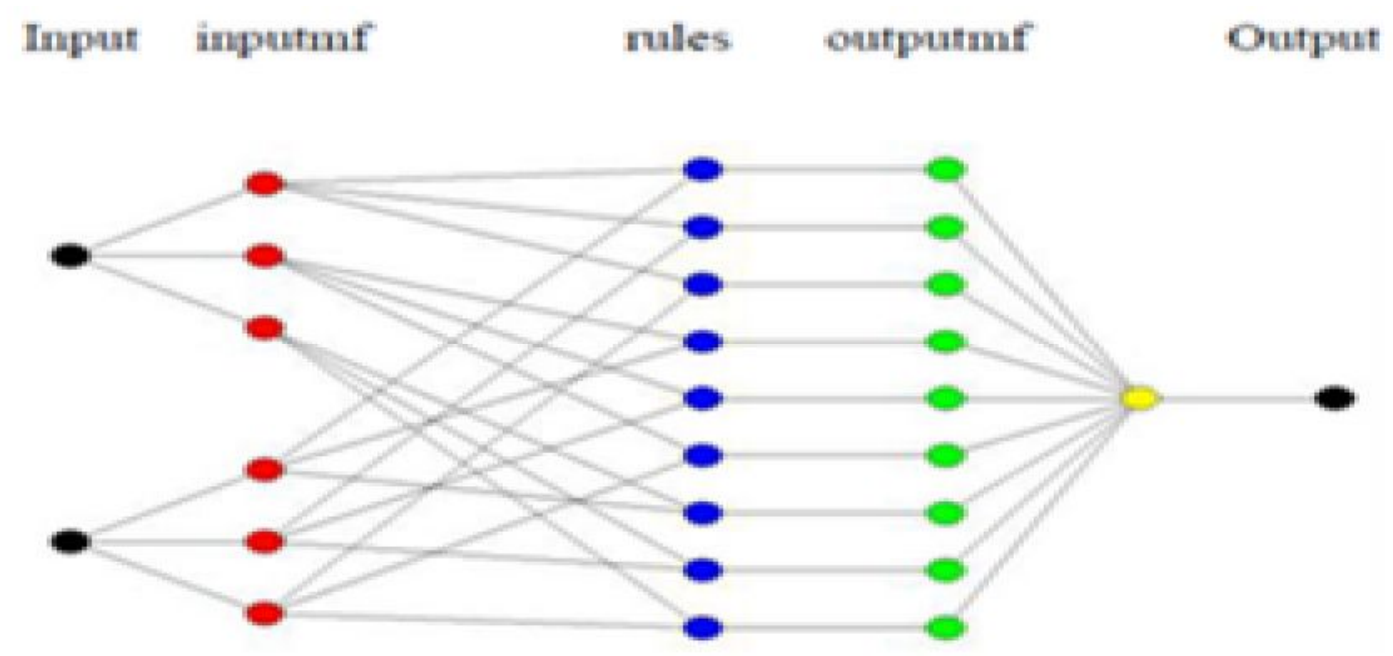

Figure(4):The Architecture Of The ANFIS

Rule 1: If $\mathrm{x}$ is $\mathrm{A}_{1}$ and $\mathrm{y}$ is $\mathrm{B}_{1}$, Then $\mathrm{Z} 1=\mathrm{c}_{1}$ (Eq.1)

Rule 2: If $\mathrm{x}$ is $\mathrm{A}_{2}$ and $\mathrm{y}$ is $\mathrm{B}_{2}$, Then $\mathrm{Z2}=\mathrm{c}_{2}$ (Eq.2) 


\section{Proposed Method:}

a) Bus Bar Modeling By ATP

A single line diagram for protected bus bar is shown in Figure.2. It is, consist of 110 $\mathrm{KV}$ bus bar systems with two feeders incoming and outgoing .The incoming feeder is connected to $110 \mathrm{KV}, 500 \mathrm{MVA}$ source. The outgoing feeder is connected to the load. Bus bar is protected by differential protection is consist of two Current Transformer (CT) with ratio 1200/ 5. The One on incoming feeder is called incoming CT. The other on outgoing feeder is called outgoing CT. The current transformer is represented by ATP as ideal transformer, Type 93 non-linear inductor ( magnetizing branch) and series resistance ( burden resistance). They are connected as shown in Figure .5. As presented in [3].Figure.7 is showing the currents wave form before and after the fault conditions which measured by the model.

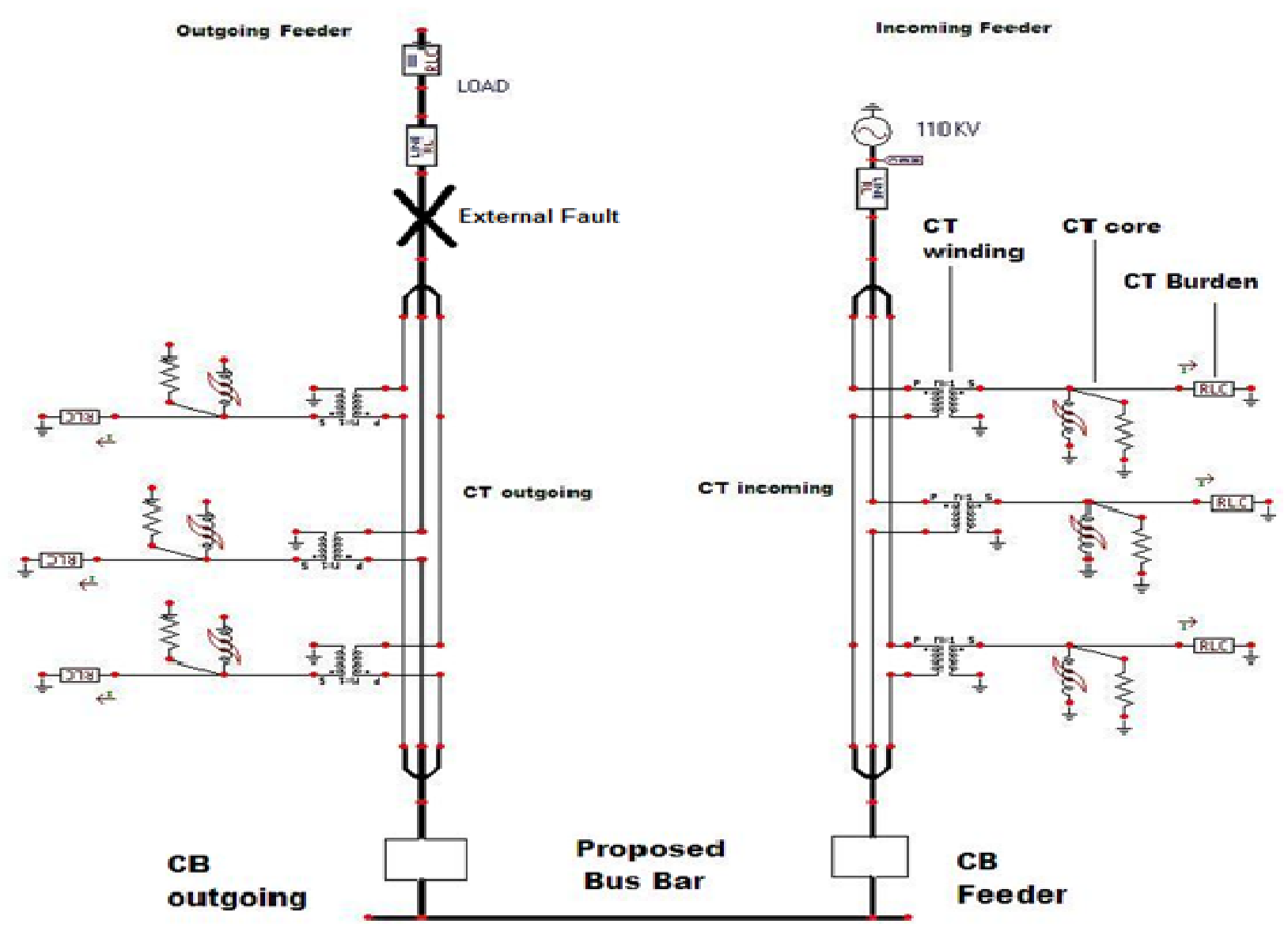

Figure(5): Single Line Diagram For The Bus Bar 
b) The Model By Matlab Simulink

The differential relay model is illustrated in Figure.6. It is consist of fault detection unit and fault location unit as given in [3 and 10].

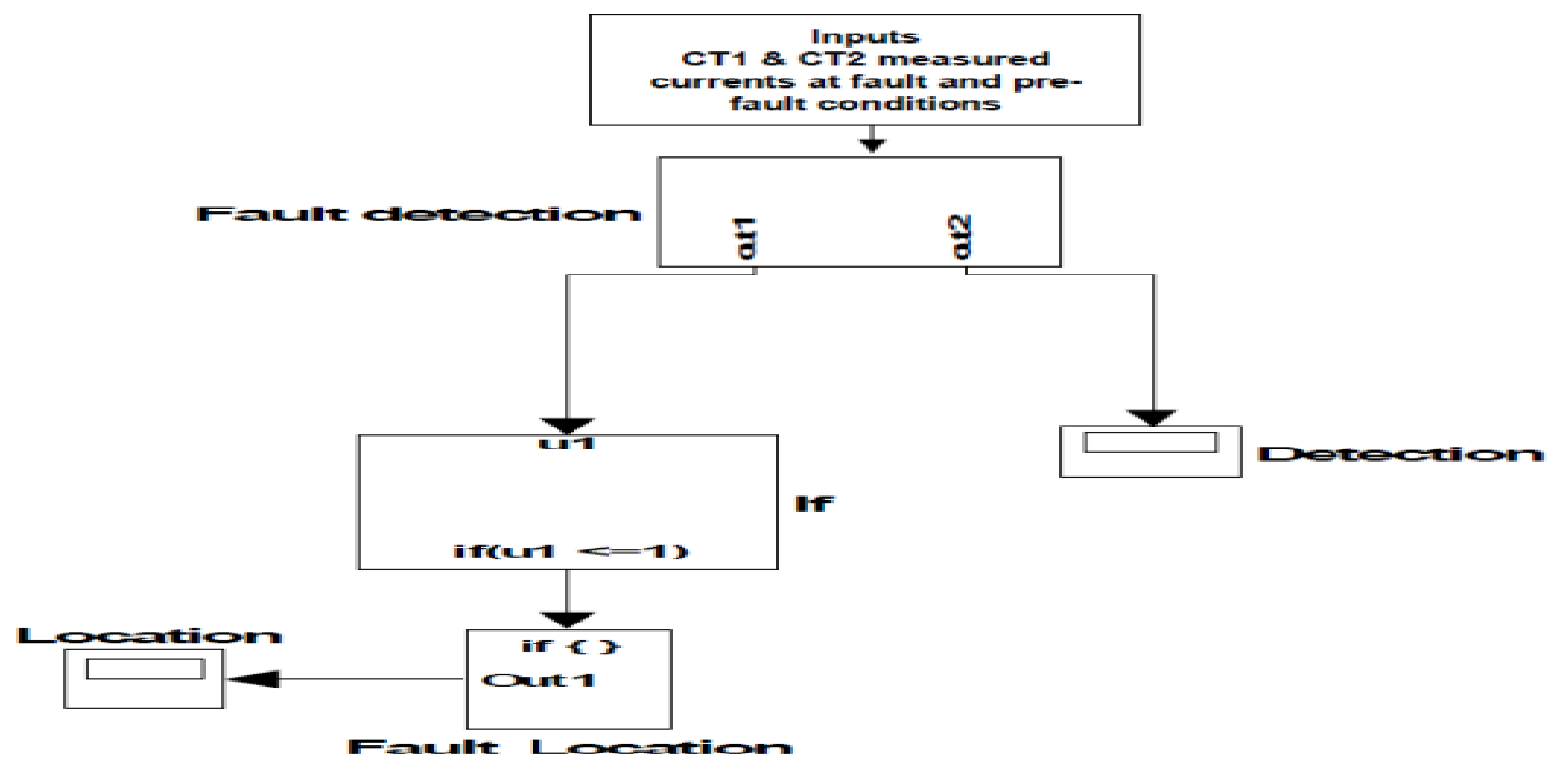

Figure(6): Differential Relay By Simulink

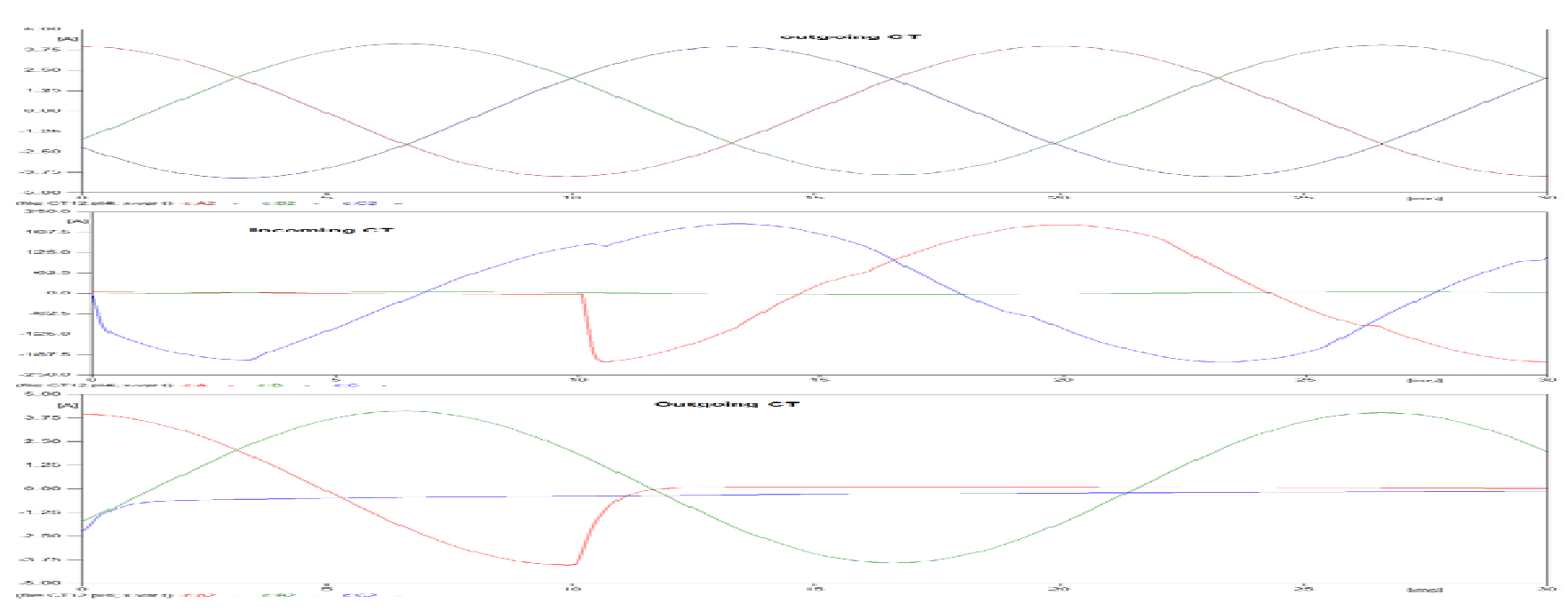

Figure(7): Pre-Fault \& Fault Currents Wave Form 


\section{ANFIS Controller Design:}

The controller design will handle two types of controller detection and location, both works together as one system to take the correct decision toward the protection system operation.

\section{a) Training Data For Fault Detection Unit:}

The training data used to train the ANFIS of the fault detection unit are taken at the nofault conditions and fault conditions. The fault conditions are carried out at all different fault types(i.e. single phase to ground, phase to phase, double phase to ground and three phase fault ) with inception fault time (Tf) $10 \mathrm{~m}$-sec and fault resistance (Rf) 0.01 , $25,50,75,100 \mathrm{ohms}$ Refer to [11] . There are many types of training data. The input data to the FNN detection unit is the difference between the positive sequence current magnitude measured by incoming CT at fault and pre-fault condition (Mag1) and the difference between the positive sequence current magnitude measured by outgoing CT at fault and pre-fault condition (Mag2). The positive sequence current is computed by discrete three phase sequence fundamental module at sampling time $0.0001 \mathrm{sec}$. While the output data from FNN is one (1) at fault condition and zero (0) at no-fault condition. As shown in Figure.6.

\section{b) Testing Data For Fault Detection Unit:}

Figure. 8 is showing the fault detection process .The testing data are chosen at different fault and no fault conditions. The fault conditions are done at different fault resistances and different fault inception times which are not chosen for the training data as given in [9]. Some of them are shown in Table.1

\section{c) Training Data For Fault Location Unit}

The training data used to train the FNN of the fault location unit are taken at all types of faults (i.e. single phase to ground

, phase to phase, double phase to ground and three phase fault ) with inception fault time (Tf) $10 \mathrm{~m}$-sec and fault resistances (Rf) $0.01,25,50,75,100 \mathrm{ohms}$ as given in [9] . There are many types of training data. The inputs data to the FNN of the location unit are the phase change of measured positive sequence current by incoming CT (Phas1) , the phase change of measured positive sequence current by outgoing CT (Phas2) as given in [10], and the difference between the measured positive sequence current magnitude of incoming CT and outgoing CT (Mag). The positive sequence current is computed by discrete three phase sequence fundamental module at sampling time $0.0001 \mathrm{sec}$. While the output data from FNN is one (1) for internal fault condition and zero (0) for external fault. As shown in Figure.9. 


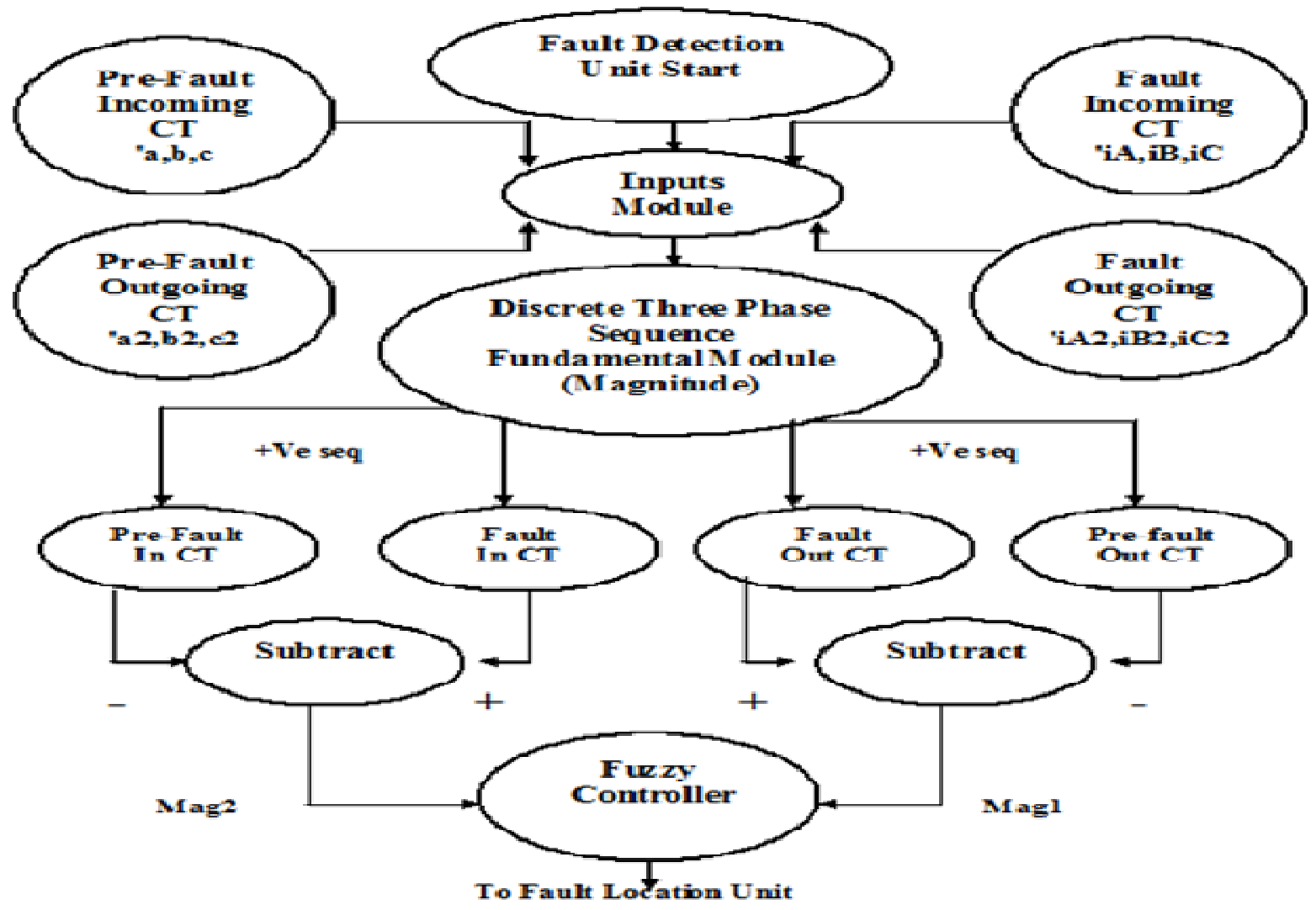

Figure (8): Fault Detection unit Operation Chart

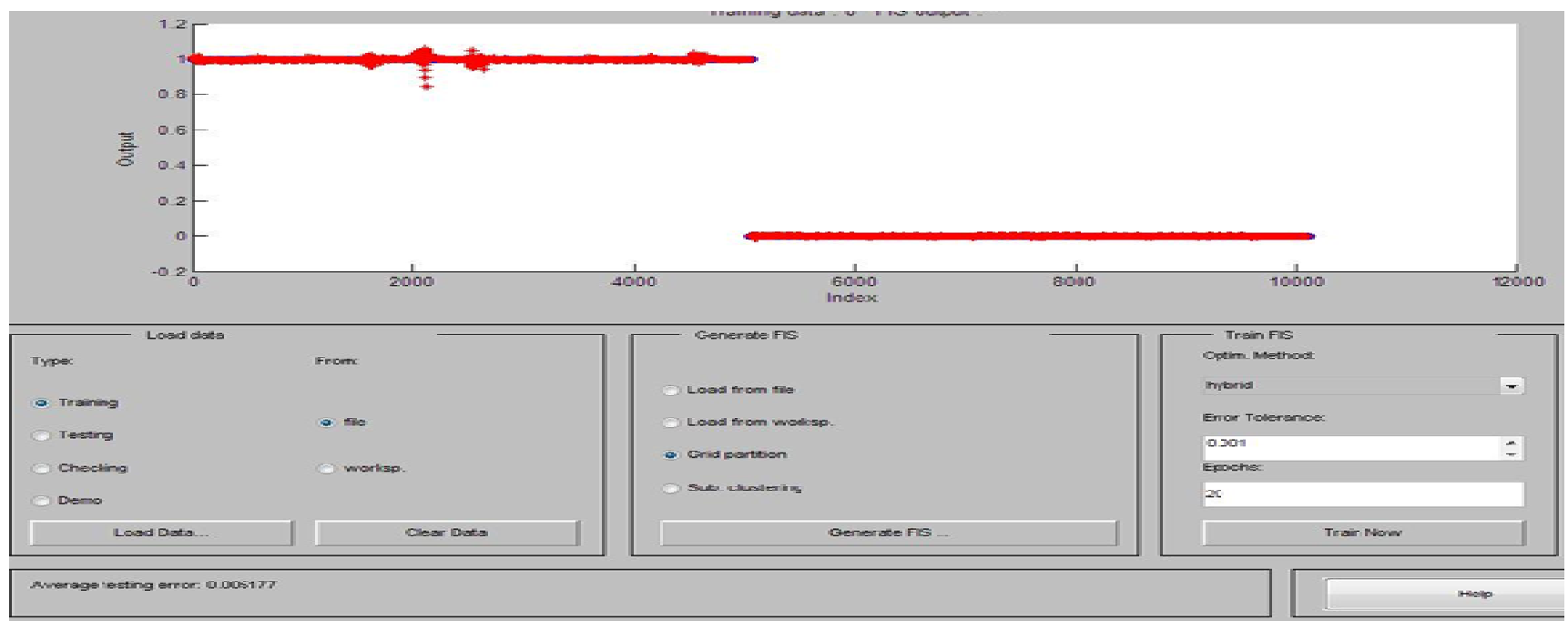

Figure (9): Fault Locator ANFIS Training Process By Matlab 


\section{d) Testing Data For Fault Location Unit:}

Figure.11 is showing fault location process. The testing data are chosen at different fault conditions which are carried out at different fault resistances and different fault inception times

which are not chosen for the training data as given in [9] .The testing data are taken randomly with random fault resistances, fault inception times and fault types in each training vector. Due to testing the old method (change at phase angle difference algorithm) is applied as given in [10]. It will be successfully when the input data already defined fault case, but for undefined fault case. The output of the controller apply the change phase angle difference algorithm will be not true, so may be that lead to maloperation of protection system. ANFIS is used for the same undefined fault cases. The change at phase angle difference for incoming, and outgoing current transformer are calculated (Phase1 \& Phase 2). The fault detection time for each fault case is detected, by comparing with the old method. ANFIS detected the fault at certain time less than the old method and the ANFIS output was (1) at internal fault and (0) for external fault like the system trained before and some of the results are show in table.2. The changing of the system parameters like source voltage and load very effective on the protection system and should be studied. The same differential protection system without any additional training process for the ANFIS controller is used. The system tested when increasing the source voltage by $2.5 \%$ and then decreasing the source voltage by $2.5 \%$. That will be on different faults types, faults resistances, fault inception time and different fault location. Also the system tested when increasing the load by $15 \%$ and then decreasing the load by $15 \%$. The testing will be on different faults types, faults resistances, fault inception time and different fault location. One of the main effective elements on the power system is the harmonics as shown in Figure.10.and Figure.12. The harmonics make great distortion in the measured current signals. As wrong information will be supplied to the protection system, and wrong action will be taken, then mal-operation for the protection system leads to black shutdown. The phase angle difference change method will not be affected by the harmonics as it is depend on the phase angle of the measured currents. On other hand if the inputs to the ANFIS controller were the harmonics current magnitudes the efficiency of the controller is still unknown comparing with phase angle difference method. 


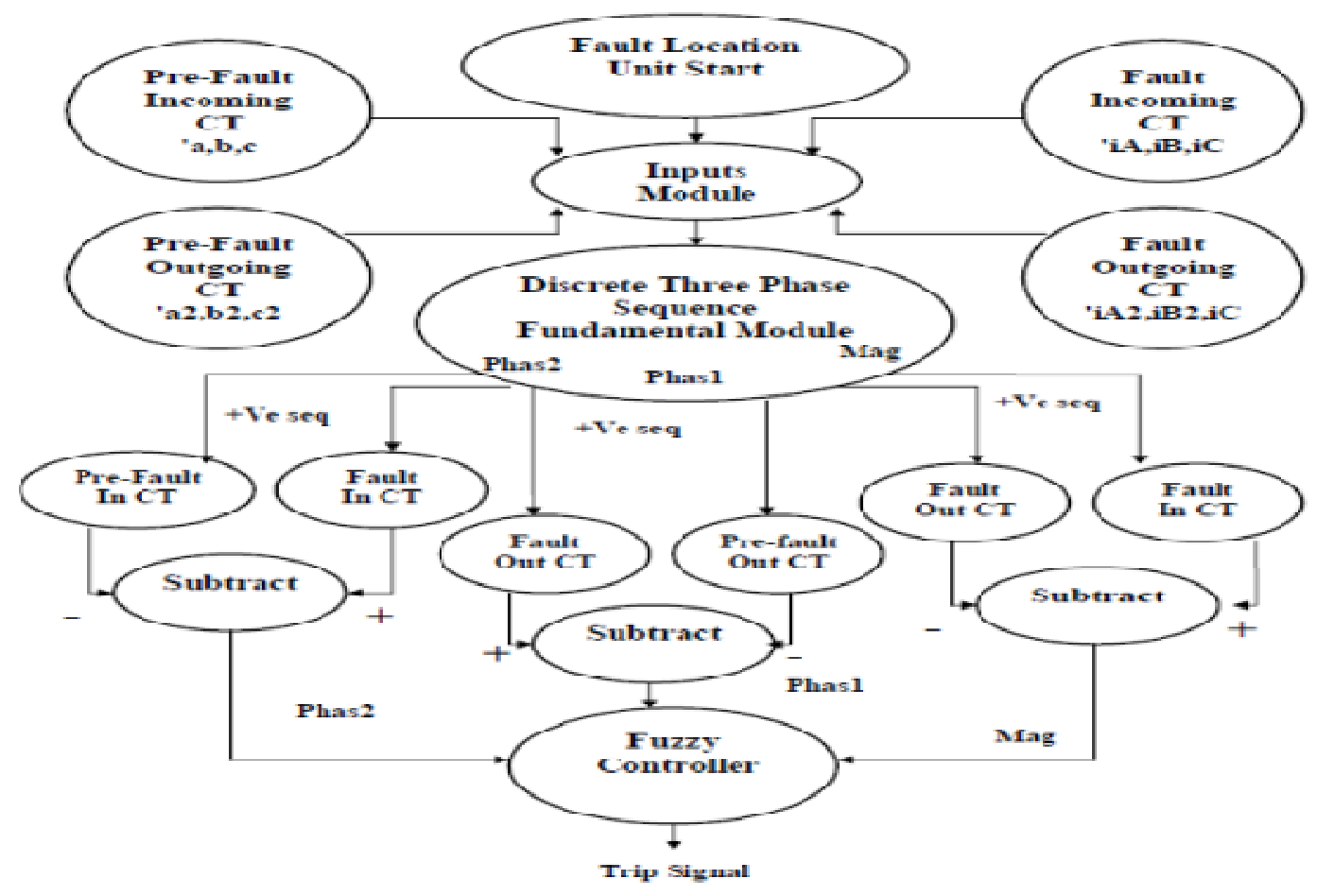

Figure(10): Fault Location unit Operation Chart

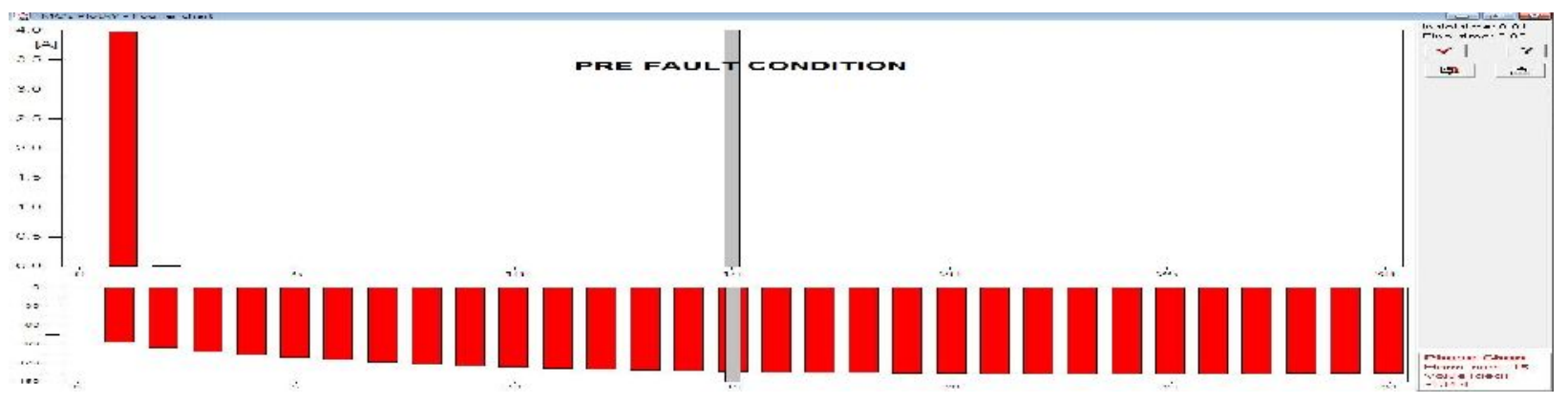

Figure(11): Pre- Fault Harmonics Analysis

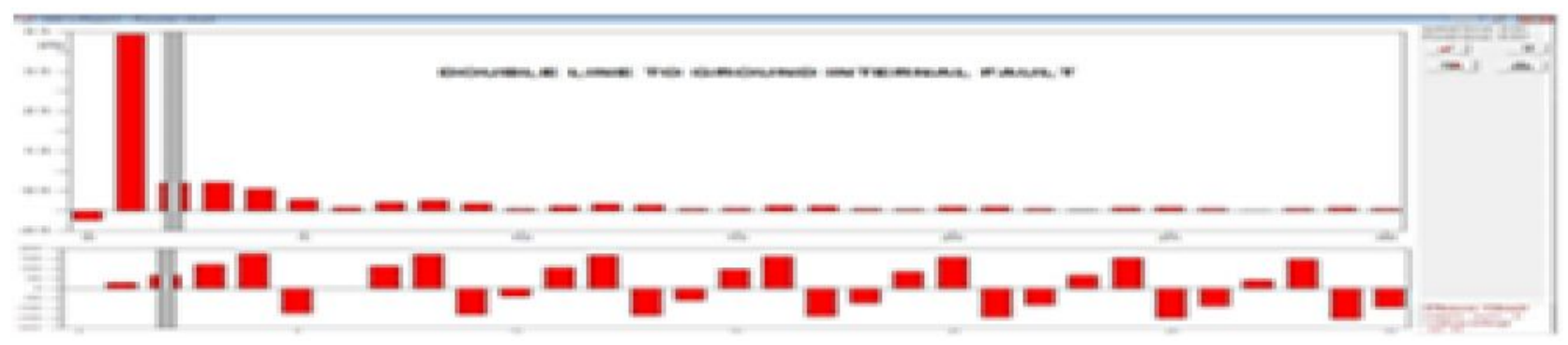

Figure(12): Fault Harmonics Analysis 


\section{Discussions:}

The testing data at different fault cases not used before due to the training process of the controller. The output of the controller was 0.999 for most fault conditions and 0.1065 at no fault condition. That is meaning the percentage of error for ANFIS at fault condition is $0.1 \%$ for most fault cases and $10 \%$ at the no -fault condition .The fault location unit is the major element at this research, as it is the concerned unit for tripping signal sending. The protection system selection depend on the time as the system should take the correct action at fault condition, sending correct tripping signal for internal fault conditions and prevent the mal-operation due to external fault conditions. On other hand, the fault clearing time is very important issue to avoid more damage at power system equipment. The fault location unit is tested at different fault cases not used before due to the training process. The output of ANFIS controller was 0.999 for most internal fault cases and 0 for external fault cases. The system success to classify the fault location at different fault cases not defined before due to the training process with percentage of error $0.1 \%$ for most internal fault conditions and nearly to $0 \%$ for external fault conditions.

Table(1): Testing Data Of The Fault Detection Unit

\begin{tabular}{|c|c|c|c|c|c|c|c|c|c|}
\hline $\begin{array}{c}\mathrm{Tf} \\
(\mathrm{Sec})\end{array}$ & $\begin{array}{c}\mathrm{Rf} \\
\text { (Ohm) }\end{array}$ & $\begin{array}{c}\text { Fault } \\
\text { type }\end{array}$ & $\begin{array}{c}\text { Fault } \\
\text { Location }\end{array}$ & $\begin{array}{c}\text { Current } \\
\text { change } \\
\text { Mag1 }\end{array}$ & $\begin{array}{c}\text { Current } \\
\text { change } \\
\text { Mag2 }\end{array}$ & $\begin{array}{c}\text { Actual } \\
\text { O/P } \\
\text { ANFIS }\end{array}$ & $\begin{array}{c}\text { expected } \\
\text { O/P } \\
\text { ANFIS }\end{array}$ & $\begin{array}{c}\text { error ANFIS } \\
\text { O/P(Expected- } \\
\text { Actual) }\end{array}$ & $\begin{array}{c}\% \text { error } \\
\text { ANFIS }\end{array}$ \\
\hline 0.014 & 18 & DLG & external & 1.3098 & 1.3098 & 0.9999 & 1 & 0.0001 & $1.00 \%$ \\
\hline 0.013 & 20 & TL & internal & 6.3054 & -0.11 & 1 & 1 & 0 & $0.00 \%$ \\
\hline 0.013 & 20 & TL & external & 6.3054 & 6.3054 & 1 & 1 & 0 & $0.00 \%$ \\
\hline 0.01 & 60 & DLG & internal & 1.0293 & -0.019 & 0.9999 & 1 & 0.0001 & $1.00 \%$ \\
\hline 0.01 & 60 & DLG & external & 1.0293 & 1.0293 & 0.9999 & 1 & 0.0001 & $1.00 \%$ \\
\hline 0.003 & 13 & DL & internal & 17.5054 & -0.3192 & 1 & 1 & 0 & $0.00 \%$ \\
\hline 0.003 & 13 & DL & external & 17.5054 & 17.5054 & 1 & 1 & 0 & $0.00 \%$ \\
\hline 0.012 & 65 & DLG & internal & 0.7452 & -0.0134 & 0.9999 & 1 & 0.0001 & $1.00 \%$ \\
\hline 0.012 & 65 & DLG & external & 0.7452 & 0.7452 & 0.9999 & 1 & 0.0001 & $1.00 \%$ \\
\hline 0.005 & 44 & SLG & internal & 2.2758 & -0.0424 & 0.9999 & 1 & 0.0001 & $1.00 \%$ \\
\hline 0.005 & 44 & SLG & external & 2.2758 & 2.2758 & 0.9999 & 1 & 0.0001 & $1.00 \%$ \\
\hline 0.003 & 61 & DL & internal & 4.577 & -0.0842 & 1 & 1 & 0 & $0.00 \%$ \\
\hline 0.003 & 61 & DL & external & 4.577 & 4.577 & 1 & 1 & 0 & $0.00 \%$ \\
\hline 0.006 & 30 & SLG & internal & 3.2782 & -0.0606 & 1 & 1 & 0 & $0.00 \%$ \\
\hline 0.006 & 30 & SLG & external & 3.2782 & 3.2782 & 1 & 1 & 0 & $0.00 \%$ \\
\hline 0.011 & 39 & TL & internal & 4.3303 & -0.0777 & 1 & 1 & 0 & $0.00 \%$ \\
\hline 0.011 & 39 & TL & external & 4.3303 & 4.3303 & 1 & 1 & 0 & $0.00 \%$ \\
\hline 0.012 & 100 & DLG & internal & 0.4882 & -0.0088 & 0.9999 & 1 & 0.0001 & $1.00 \%$ \\
\hline 0.012 & 100 & DLG & external & 0.4882 & 0.4882 & 0.9999 & 1 & 0.0001 & $1.00 \%$ \\
\hline 0.002 & 37 & TL & internal & 9.5426 & -0.1821 & 1 & 1 & 0 & $0.00 \%$ \\
\hline
\end{tabular}


Table(2): Testing Data Of The Fault Location Unit

\begin{tabular}{|c|c|c|c|c|c|c|c|c|}
\hline $\begin{array}{c}\text { Tf } \\
(\mathrm{sec})\end{array}$ & $\begin{array}{c}\mathrm{Rf} \\
(\mathrm{Ohm})\end{array}$ & $\begin{array}{c}\text { Fault } \\
\text { Type }\end{array}$ & $\begin{array}{c}\text { Fault } \\
\text { Location }\end{array}$ & $\begin{array}{c}\text { Phase 1 } \\
\text { Difference } \\
\text { (Rad) }\end{array}$ & $\begin{array}{c}\text { Phase 2 } \\
\text { Difference } \\
\text { (Rad) }\end{array}$ & $\begin{array}{c}\text { Detection } \\
\text { Fault } \\
\text { Time } \\
\text { Old } \\
\text { Method(Sec) }\end{array}$ & $\begin{array}{c}\text { ANFIS } \\
\text { O/P }\end{array}$ & $\begin{array}{c}\text { Detection } \\
\text { Fault } \\
\text { Time } \\
\text { ANFIS(Sec) }\end{array}$ \\
\hline 0.023 & 91 & DL-G & Internal & -0.0106 & 0.0000 & 0.0318 & 1 & 0.0242 \\
\hline 0.023 & 91 & DL-G & External & -0.0106 & -0.0106 & 0.0318 & 0 & 0.0318 \\
\hline 0.027 & 54 & TL & Internal & -0.0101 & 0.0000 & 0.0322 & 1 & 0.0276 \\
\hline 0.027 & 54 & TL & External & -0.0101 & -0.0101 & 0.0322 & 0 & 0.0322 \\
\hline 0.022 & 78 & DL-G & Internal & -0.0118 & 0.0000 & 0.0311 & 1 & 0.0230 \\
\hline 0.022 & 78 & DL-G & External & -0.0118 & -0.0118 & 0.0311 & 0 & 0.0311 \\
\hline 0.021 & 74 & SLG & Internal & -0.0110 & 0.0000 & 0.0286 & 1 & 0.0223 \\
\hline 0.021 & 74 & SLG & External & -0.0110 & -0.0110 & 0.0286 & 0 & 0.0286 \\
\hline 0.026 & 3 & DL-G & Internal & -0.0276 & 0.0000 & 0.0306 & 1 & 0.0264 \\
\hline 0.026 & 3 & DL-G & External & -0.0276 & -0.0276 & 0.0306 & 0 & 0.0306 \\
\hline 0.022 & 22 & TL & Internal & -0.0105 & 0.0000 & 0.0275 & 1 & 0.0224 \\
\hline 0.022 & 22 & TL & External & -0.0105 & -0.0105 & 0.0275 & 0 & 0.0275 \\
\hline 0.026 & 86 & DL & Internal & -0.0115 & 0.0000 & 0.0276 & 1 & 0.0287 \\
\hline
\end{tabular}

Table(3): Fault Location Unit At $+2.5 \%$ Of Source Voltage

Festing Faulr Locarion Unix Ar $+2.5 \%$ of Source Volrage:

\begin{tabular}{|c|c|c|c|c|c|c|c|c|}
\hline \multirow[b]{2}{*}{$\begin{array}{c}\text { Tf } \\
\text { (Sec) }\end{array}$} & \multirow[b]{2}{*}{$\begin{array}{c}\text { Rf } \\
(\mathrm{Ohm})\end{array}$} & \multirow[b]{2}{*}{$\begin{array}{l}\text { Fault } \\
\text { Type }\end{array}$} & \multirow[b]{2}{*}{$\begin{array}{c}\text { Fault } \\
\text { Location }\end{array}$} & \multicolumn{2}{|c|}{ Phase Angle Method } & \multicolumn{3}{|c|}{ ANFIS Method } \\
\hline & & & & $\begin{array}{c}\text { Phase } 1 \\
\text { Difference } \\
\text { (Rad) }\end{array}$ & $\begin{array}{c}\text { Phase } 2 \\
\text { Difference } \\
\text { (Rad) }\end{array}$ & $\begin{array}{l}\text { Detection } \\
\text { Fault } \\
\text { Time } \\
\text { Old } \\
\text { Method } \\
\text { (Sec) }\end{array}$ & $\begin{array}{c}\text { ANFIS } \\
\text { O/P }\end{array}$ & $\begin{array}{l}\text { Detection } \\
\text { Fault } \\
\text { Time } \\
\text { ANFIS } \\
\text { (Sec) }\end{array}$ \\
\hline 0.023 & 91 & DL-G & Internal & -0.010758 & 0.0002025 & 0.0247 & 1 & 0.0241 \\
\hline 0.023 & 91 & DL-G & External & -0.010758 & -0.010758 & 0.0247 & $\mathbf{o}$ & 0.0247 \\
\hline 0.027 & 54 & TL & Internal & -0.000903 & $\mathbf{0}$ & 0.0276 & 1 & 0.0276 \\
\hline 0.027 & 54 & TL & External & -0.000903 & -0.000903 & 0.0276 & $\mathbf{o}$ & 0.0276 \\
\hline 0.021 & 74 & SLG & Internal & -0.023275 & 0.0003539 & 0.0223 & 1 & 0.0223 \\
\hline 0.021 & 74 & SLG & External & -0.023275 & -0.023275 & 0.0223 & $\mathbf{O}$ & 0.0223 \\
\hline 0.026 & 86 & DL & Internal & 0.060445 & -0.000842 & 0.0287 & 1 & 0.0287 \\
\hline 0.026 & 86 & DL & External & 0.060445 & 0.0604451 & 0.0287 & $\mathbf{O}$ & 0.0287 \\
\hline
\end{tabular}

Table(4): Fault Location Unit at -2.5\% Of Source Voltage

\begin{tabular}{|c|c|c|c|c|c|c|c|c|}
\hline \multirow[b]{2}{*}{$\begin{array}{c}\text { Tf } \\
\text { (Sec) }\end{array}$} & \multirow[b]{2}{*}{$\begin{array}{c}\text { Rf } \\
\text { (Ohm) }\end{array}$} & \multirow[b]{2}{*}{$\begin{array}{l}\text { Fault } \\
\text { Type }\end{array}$} & \multirow[b]{2}{*}{$\begin{array}{c}\text { Fault } \\
\text { Location }\end{array}$} & \multicolumn{2}{|c|}{ Phase Angle Method } & \multicolumn{3}{|c|}{ ANFIS Method } \\
\hline & & & & $\begin{array}{c}\text { Phase } 1 \\
\text { Difference } \\
\text { (Rad) }\end{array}$ & $\begin{array}{c}\text { Phase } 2 \\
\text { Difference } \\
\text { (Rad) }\end{array}$ & $\begin{array}{l}\text { Detection } \\
\text { Fault } \\
\text { Time } \\
\text { Old } \\
\text { Method } \\
\text { (Sec) }\end{array}$ & $\begin{array}{c}\text { ANFIS } \\
\text { O/P }\end{array}$ & $\begin{array}{l}\text { Detection } \\
\text { Fauit } \\
\text { Time } \\
\text { ANFIS } \\
\text { (Sec) }\end{array}$ \\
\hline 0.023 & 91 & DL-G & Internal & -0.010758 & 0.0002025 & 0.0247 & 1 & 0.0242 \\
\hline 0.023 & 91 & DL-G & External & -0.010758 & -0.010758 & 0.0247 & o & 0.0247 \\
\hline 0.027 & 54 & TL & Internal & -0.000902 & $\mathbf{0}$ & 0.0276 & 1 & 0.0276 \\
\hline 0.027 & 54 & TL & External & -0.000902 & -0.000902 & 0.0276 & $\mathbf{0}$ & 0.0276 \\
\hline 0.021 & 74 & SLG & Internal & -0.023275 & 0.0003539 & 0.0223 & 1 & 0.0223 \\
\hline 0.021 & 74 & SLG & External & -0.023275 & -0.023275 & 0.0223 & $\mathbf{O}$ & 0.0223 \\
\hline 0.026 & 86 & DL & Internal & -0.020793 & 0.0002111 & 0.0266 & 1 & 0.0266 \\
\hline 0.026 & 86 & DL & External & -0.020793 & -0.020793 & 0.0266 & $\mathbf{0}$ & 0.0266 \\
\hline
\end{tabular}


Table(5): Fault Location Unit at $+15 \%$ Of Load

Tesring Faulr Locarion Umir ar +15\% Of Load:

\begin{tabular}{|c|c|c|c|c|c|c|c|c|}
\hline \multirow[b]{2}{*}{$\begin{array}{c}\text { Tf } \\
(\mathrm{Sec})\end{array}$} & \multirow[b]{2}{*}{$\begin{array}{c}\text { Rf } \\
(\mathrm{Ohm})\end{array}$} & \multirow[b]{2}{*}{$\begin{array}{l}\text { Fault } \\
\text { Type }\end{array}$} & \multirow[b]{2}{*}{$\begin{array}{c}\text { Fault } \\
\text { Location }\end{array}$} & \multicolumn{2}{|c|}{ Phase Angle Method } & \multicolumn{3}{|c|}{ ANFIS Method } \\
\hline & & & & $\begin{array}{c}\text { Phase } 1 \\
\text { Difference } \\
\text { (Rad) }\end{array}$ & $\begin{array}{c}\text { Phase } 2 \\
\text { Difference } \\
\text { (Rad) }\end{array}$ & $\begin{array}{l}\text { Detection } \\
\text { Fault } \\
\text { Time } \\
\text { Old } \\
\text { Method } \\
\text { (Sec) }\end{array}$ & $\begin{array}{l}\text { ANFIS } \\
\text { O/P }\end{array}$ & $\begin{array}{l}\text { Detection } \\
\text { Fault } \\
\text { Time } \\
\text { ANFIS } \\
\text { (Sec) }\end{array}$ \\
\hline 0.023 & 91 & DL-G & Internal & -0.01037 & 0.0002313 & 0.0248 & $\mathbf{1}$ & 0.0242 \\
\hline 0.023 & 91 & DL-G & External & -0.01037 & -0.01037 & 0.0248 & $\mathbf{O}$ & 0.0248 \\
\hline 0.027 & 54 & TL & Internal & -0.000771 & $\mathbf{O}$ & 0.0276 & 1 & 0.0276 \\
\hline 0.027 & 54 & TL & External & -0.000771 & -0.000771 & 0.0276 & $\mathbf{O}$ & 0.0276 \\
\hline 0.021 & 74 & SLG & Internal & -0.019857 & $\mathbf{O}$ & 0.0223 & 1 & 0.0223 \\
\hline 0.021 & 74 & SLG & External & -0.01072 & -0.01072 & 0.0218 & $\mathbf{O}$ & 0.0218 \\
\hline 0.026 & 86 & DL & Internal & 0.051594 & -0.000841 & 0.0287 & 1 & 0.0287 \\
\hline 0.026 & 86 & DL & External & 0.012783 & 0.012783 & 0.0277 & $\mathbf{0}$ & 0.0277 \\
\hline
\end{tabular}

Figure(6): Fault Location Unit at $-15 \%$ Of Load

\begin{tabular}{|c|c|c|c|c|c|c|c|c|}
\hline \multirow[b]{2}{*}{$\begin{array}{c}\text { Tf } \\
(S e c)\end{array}$} & \multirow[b]{2}{*}{$\begin{array}{c}\text { Rf } \\
\text { (Ohm) }\end{array}$} & \multirow[b]{2}{*}{$\begin{array}{l}\text { Fault } \\
\text { Type }\end{array}$} & \multirow[b]{2}{*}{$\begin{array}{c}\text { Fault } \\
\text { location }\end{array}$} & \multicolumn{2}{|c|}{ Phase Angle Method } & \multicolumn{3}{|c|}{ ANFIS Method } \\
\hline & & & & $\begin{array}{c}\text { Phase 1 } \\
\text { Difference } \\
\text { (Rad) } \\
\text {-0.0108 }\end{array}$ & $\begin{array}{c}\text { Phase } 2 \\
\text { Difference } \\
\text { (Rad) } \\
0.000175\end{array}$ & $\begin{array}{l}\text { Detection } \\
\text { Fault } \\
\text { Time } \\
\text { Old } \\
\text { Method } \\
\text { (Sec) } \\
0.0246\end{array}$ & $\begin{array}{c}\text { ANFIS } \\
\text { O/P }\end{array}$ & $\begin{array}{c}\text { Detection } \\
\text { Fault } \\
\text { Time } \\
\text { ANFis } \\
\text { (Sec) } \\
0.0242\end{array}$ \\
\hline 0.023 & 91 & DL-G & External & -0.0108 & -0.0108 & 0.0246 & $\mathbf{o}$ & 0.0246 \\
\hline 0.027 & 54 & TL & Internal & -0.001032 & $\mathbf{O}$ & 0.0276 & 1 & 0.0276 \\
\hline 0.027 & 54 & TL & External & -0.001032 & -0.001032 & 0.0276 & $\mathbf{O}$ & 0.0276 \\
\hline 0.021 & 74 & SLG & Internal & -0.026654 & 0.0003544 & 0.0223 & 1 & 0.0223 \\
\hline 0.021 & 74 & SLG & External & -0.026654 & -0.026654 & 0.0223 & $\mathbf{o}$ & 0.0223 \\
\hline 0.026 & 86 & DL & Internal & 0.0692029 & -0.000842 & 0.0287 & 1 & 0.0287 \\
\hline 0.026 & 86 & DL & External & 0.0692028 & 0.069203 & 0.0287 & $\mathbf{o}$ & 0.0287 \\
\hline
\end{tabular}

\section{Conclusions:}

In this research the major conclusions obtained could be summarized as follows: An Artificial Intelligent approach of bus bar differential protection for fault detection and location in distribution system protection was introduced in this research. The proposed approach demonstrates successful performance for the two main protection tasks. For the fault detection task, all the testing data for the ANFIS detectors give the correct output within the given periods that are mentioned before. For the fault location task, all the testing data for the ANFIS locator units give the correct estimated output with minimum error. Moreover, the testing procedure takes into account the randomness of the faults on distribution feeder with respect to the time of occurrence, fault location, fault type and resistance. The phasor concept is used to overcome the current transformer saturation and mismatch. The proposed technique is not using the voltage signal for discriminating the fault location. 


\section{References:}

[1] Power System Protection, Newnes an imprint of Elsevier, 2004.

[2] M.R Ahaebrahimi , H.Khorashadizadeh, Fuzzy Neuro Approach To Bus Bar Protection Design And Implementation , International Journal Of Information Technology Number, Iran , 2005.

[3] Tamer Sayed Saleh, A Novel Approach To Distance Protection Of Transmission Lines Using Adaptive Neuro Fuzzy Inference System, M.Sc.thesis Cairo University Faculty of Engineering Department of Electrical Power And Machines, 2011.

[4] Arun .G. Phadke \& James. S. Throp, Computer relaying for power systems. Research Studies Press LTD (RSP) and JOHN WILEY \&SONS INC,1988.

[5] Ralph Folkers, Determine Current Transformer Suitability Using EMTP Models, Schweitzer Engineering Laboratories, INC. Pullman .WA USA, 1999.

[6] N.W. Kinhekar, Sangeet. A Daingade , and Ajayshree Kinhekar , Current Differential Protection Of Alternator Stator Winding , International Conference On Power System Transients (IPST2009) In Kyoto, Japan June, 2009 .

[7] Bodankasztenny, Gustawo Brunello and Lumomin Sevov Digital Low Impedance Bus Differential Protection With Reduced Requirements For C.T, GE Power Mangement CANADA

[8] Transmission And Distribution Conference and Exposition 2001, IEEE/PES Volume 2, Issue, 2001, Pages: 703-708 VOL.2

[9] J.G Andrichak and Jorge Cardenas , Bus Differential Protection, Western Protective Relay Conference Spoken, Washington , October 24 ,1995 .

[10] Mohamed Salah El-din Ahmed, An Artificial Intelligence Approach For High Impedance Faults Detection, Classification And Location In Distribution Systems Using Adaptive Neuro Fuzzy Inference Systems. M.Sc.thesis, Cairo UN, Faculty of Engineering. 
[11] P.Jena and A.Kpradham , Busbar Protection A Solution To C.T Saturation, Fifteenth National Power System Conference (NPSC,ITT) Bombay Dec-2008

[12] S.N.Sivanandam, S.S Sumathi and S.N Deepa, Introduction To Fuzzy Logic Using Mat-lab, Springer Science, 2007.

[13] N.W. Kinhekar, Sangeeta Daingade, and Kinhekar , Current Differential Protection Of Alternator Stator Winding , International Conference On Power Systems Transients (IPST2009) In Kyoto, Japan June, 2009 .

[14] Shiyong Wang, Xinzhou Dong, and Shenxing Shi, A Novel Bus Bar Protection Scheme Based Wavelet Multi - Resolution Signal Decomposition. 10th IET International Conference on Developments in Power System Protection (DPSP 2010)

[15] Y.C.kang, J.S.Yun, B.E.Lee, S.H.Lee, S.H.Kang, S.I.Jang and Y.G.Kim , Bus Bar Differential Protection In Conjunction With A Current Transformer Compensating Algorithm, IET Gener, Transm . Distrib .Vol.2, No, 1, Jan 2008.

[16] A.M.Dmitrienko and A.Y.U.Sinichkin, Dec-16-2010, Fast Differential Bus Bar Protection Based On REB670, Russian Electrical Engineering.

[17] M.E.Mohammed , High Speed Differential Bus Bar Protection Using Wavelet -Packet Transform, Electrical Engineering Department, Faculty Of Engineering, Helwan University, Cairo, Egypt .

[18] S.R.Samantaray , L.N.Tripathy , P.K.Dash , G.Panda , S-Transform Based Directional Bus Bar Protection, National Institute Of Technology, Rourkela , India and Siliscon Instituted of Technology Bhubanes war, India .

[19] K.alus.Peter Brand, senior member, IEEE, and Wolfgang Wimmer. Use Of Distribution Topology Detection for Applications In Substation Automation, IEEE Bucharest power Tech conference, Jun $28^{\text {th }}-$ Jul 2 nd -2009, Romania.

[20] Zahra Moravej, Moshanir Co. Minimal Radial Basis Function Network Based Bus Protection System Using OCT, protection \& Control Division, Tahran, Iran.

[21] M.M.Eissa , A Novel Wavelet Approach To Bus Bar Protection During CT Saturation And Ratio Mismatch, Department Of Electrical Engineering, Faculty Of Engineering , Helwan university , Helwan , Cairo ,Egypt , 30-Jul-2003 
[22] MATLAB, Version 7.6.0.324 (R2008a), product of Math works, inc. Trade Mark.

[23] ATP, windows version 3.5P11, 2001, SINTEF energy research

[24] Keivin.M.Passino, Stephen Yurkovich. Fuzzy Control, Addison-Wesley.1998.

\section{Nomenclatures:}

Tf Fault Time

Rf Fault Resistance 